\title{
A TEORIA DA CORRUPÇÃO (DOBEL): OS PODERES E O ESTADO
}

\section{DOBEL'S CORRUPTION THEORY: DEPARTAMENTS AND STATE}

\section{MARIA GARCIA}

Procuradora do Estado de São Paulo (IPESP). Ex-Assistente Jurídico da Reitoria da USP. Professora Associada Livre-Docente da PUC/São Paulo. Professora de Direito Constitucional, Direito Educacional e Biodireito Constitucional. Professora de Biodireito/Bioética/Biopolítica do Centro Universitário Assunção - UNIFAI. Membro da $\mathrm{CoBi}$ - Comitê de Bioética do HCFMUSP. Membro do Instituto dos Advogados de São Paulo/IASP. Membro fundador e atual Diretora-Geral do Instituto Brasileiro de Direito Constitucional (IBDC). Coordenadora da Revista de Direito Constitucional e Internacional (Editora Revista dos Tribunais). Membro da Academia Paulista de Letras Jurídicas (Cadeira Enrico T. Liebman). Associada Honorária do CONPEDI. Membro do Conselho Superior de Direito da Federação do Comércio FECOMERCIO. Membro do Conselho Editorial da Revista da Escola Superior da Procuradoria-Geral do Estado de São Paulo. Membro do Conselho Editorial da Revista De Jure, do MPMG - Ministério Público de Minas Gerais. Consultora Nacional da Comissão de Direito Constitucional da OAB/RJ

\section{RESUMO}

Aplicação da Teoria da Corrupção, de John Patrick Dobel à atualidade política, objetivando o seu combate, pelo aperfeiçoamento da Cidadania, com ênfase na Educação.

PALAVRAS-CHAVES: Estado; Corrupção; Facções; Poderes; Crise. 


\begin{abstract}
Application of State's Corruption, Dobel's Theory, to the present situation, having in view Citizenship's improvement, with emphasis on education.
\end{abstract}

KEYWORDS: State; Corruption; Factions; Departments; Crisis.

\title{
INTRODUÇÃO
}

O passar do tempo mostra, com certa impaciência, que determinados valores permanecem como tais, consagrados pelas culturas, apesar de algumas idéias da Modernidade.

Assim a sempre ensinada Teoria da Separação dos Poderes na qual Montesquieu não pretende senão a defesa da liberdade politica do individuo diante do poder estatal, assim dividido, em suas funções, porquanto, "il faut que, par disposition des choses, le pouvoirt arrête le pouvoir". (HAURIOU, 1975, p.236)

A partir daí, uma advertência de Loewenstein sobre liberdade política e propaganda, questão básica na atualidade, em especial com a existência e desenvolvimento das novas tecnologias da informação e "os meios de comunicação de massa".

$\mathrm{Na}$ atualidade, portanto, observa-se profunda crise entre os Poderes, contrariamente ao espírito do comando constitucional constante do art. $2^{\circ}$ quando refere "independentes e harmônicos entre si" - estabelecendo "o mecanismo de freios e contrapesos caracterizador da harmonia entre os Poderes", refere José Afonso da Silva (2005, p.45), acrescentando:

Tudo isso demonstra que trabalhos do Legislativo e do Executivo, especialmente, mais também do Judiciário, só se desenvolverão a bom termo se esses órgãos se subordinarem ao princípio da harmonia, que não significa nem o domínio de um pelo outro, nem a usurpação de atribuições, mas a verificação de que entre eles há de haver consciente colaboração e controle recíproco (que, aliás, integra o mecanismo), para evitar distorções 
e desmandos. A desarmonia, porém, se dá sempre que se acrescem atribuições, faculdades e prerrogativas de um em detrimento de outro.

Trata-se de uma forma sutil de corrupção ${ }^{1}$, questão desenvolvida por John Patrick Dobel em "Como e porque um Estado se corrompe", apresentada em cinco proposições, até "a corrupção final do Estado".

Que envolve, nos dias atuais, a chamada crise dos Poderes "com forte impacto de funcionamento entre instituições", refere Oscar Vilhena Vieira, a "expansão da jurisdição constitucional" e a "reiterada omissão legislativa" de que trata Glauco Salomão Leite - tendo, como pano de fundo, o mandamento do citado art. $2^{\circ}$ da Constituição Federal de 1998.

A Teoria de Dobel propõe, como solução, a ênfase no que denomina "estruturas primárias", dentre as quais a educação e a vida familiar que, por sua vez, encontram-se em crise extrema na sociedade atual.

Temas que encontram fundamento na Constituição, expressamente, a família como "base da sociedade", que "tem especial proteção do Estado" (art. 226) e a educação, "visando ao pleno desenvolvimento da pessoa, seu preparo para o exercício da cidadania e sua qualificação para o trabalho" (art. 205).

Portanto Cidadão, Estado e a Lei Fundamental ___ fundamentos da Nação.

\section{MONTESQUIEU, AINDA}

Poder, na acepção de Max Weber (1994, p.33), significa toda a probabilidade de impor a própria vontade numa relação social, mesmo contra resistências, seja qual for o fundamento dessa probabilidade ${ }^{2}$.

\footnotetext{
1 "Do latim corruptio, ação ou efeito de corromper, de fazer degenerar" (Larousse Cultural, Nova Cultural, 1998)

2 "Dominação", distingue, "é a probabilidade de encontrar obediência a uma ordem de determinado conteúdo, entre determinadas pessoas indicáveis; disciplina é a probabilidade de encontrar obediência pronta, automática e esquemática a uma ordem, entre uma pluralidade indicável de pessoas, em virtude de atividades treinadas".
} 
Essa feição do fenômeno poder vem trabalhada em Maquiavel, quando inicia "O Príncipe" com a famosa frase: "Todos os Estados, todos os domínios que têm havido e que há sobre os homens, foram e são republicas ou principados"3. Comenta o tradutor Lívio Xavier, no Prefácio:

"O Príncipe" reflete as condições da época na qual e para a qual foi escrito,
a reforma política, o livre exame dos fatos históricos, o ataque às tradições
medievais, a instituição do êxito como única medida do poder do príncipe
enfim, a ruptura do temporal com o espiritual. (...) A sua grandeza e
originalidade consiste, (...) em ter alargado o campo da ciência na política,
distinguindo os interesses políticos primários das classes mas confundindo-
os, ao mesmo tempo, em uma monstruosa razão de Estado pela qual o
povo é apenas matéria plástica nas mãos do Príncipe. Confundem-se o mito
do maquiavelismo e o da razão do Estado.

Daí a frase lapidar de Montesquieu (1987, p.165) "A liberdade política num cidadão, é aquela tranquilidade de espírito que provém da convicção que cada um tem da sua segurança. Para ter-se essa liberdade é preciso que o governo seja tal que cada cidadão não possa temer outro cidadão".

E com antecedentes em Aristóteles e Locke (235-236), a sua proposta da separação dos Poderes, aludindo à Constituição inglesa:

Há uma nação no mundo que tem por objetivo direto de sua Constituição a liberdade política. Vamos examinar os princípios sobre os quais a fundamenta. Se são bons, a liberdade aparecerá ali como num espelho.

Referindo-se à liberdade política, aponta a tendência humana do detentor do poder abusar do poder até encontrar limites. Portanto:

Para que não se possa abusar do poder é preciso que, pela disposição das coisas, o poder detenha o poder. (...) Tudo seria perdido se o mesmo homem, ou o mesmo colégio de príncipes ou de nobres, ou de povo, exercessem os três poderes: 0 de fazer as leis, o de executar as resoluções públicas e o de julgar os crimes ou conflitos entre particulares.

Hauriou $(237,239)$ comenta que Montesquieu, diversamente de Locke, inscreve o Judiciário na lista de Poderes "mas se apercebe, ao mesmo tempo, que o

${ }^{3}$ Ediouro, Rio de Janeiro, s/data 
dialogo fundamental tem lugar entre o Executivo e o Legislativo", anotando, adiante, que "a boa leitura de Montesquieu", contrariamente àquelas que sublinham a rigidez da separação, "no capítulo sobre a Constituição inglesa, tratando das relações entre o Parlamento e o Governo do Rei, declara:

\begin{abstract}
Esses poderes deverão apresentar uma pausa ou uma inação (devido à faculdade de impedir-se mutuamente que Montesquieu declara pertencerIhes); mas, como pelo movimento necessário das coisas, eles serão forçados a caminhar de acordo. (...) A caminhar conciliadoramente, conforme preceitua a Constituição Federal de 1988, art. 20: São Poderes da União independentes e harmônicos entre si, o Legislativo, o Executivo e o Judiciário.
\end{abstract}

Explica Meirelles Teixeira (2011, p.523):

Os titulares do exercício do poder político não o são, portanto, como já vimos ao tratarmos da representação, por direito próprio mas como delegados da nação soberana, como titulares de meras faculdades e competências estatais. Cada órgão exerce apenas, como nota Michoud, na esfera de sua competência, o poder político unitário do Estado. Se, entretanto, uno é o poder político em sua origem, em sua essência e em sua atuação originária, através do Poder Constituinte, ele se divide, todavia, em seu exercício, já pela sua natureza racional e responsável, já pelo princípio da divisão de trabalho, para atender à complexidade das tarefas estatais e à consequente necessidade de especialização dos órgãos estatais, no desempenho dessas tarefas. (...) É incorreto, portanto, falar-se em "divisão do poder político" pois este não se divide. Dividem-se as funções, os atos em que se concretiza o exercício do poder ${ }^{4}$.

Daí que ao tratar-se da "corrupção do Estado" adentra-se, efetivamente, a corrupção dos Poderes, pessoas exercentes das funções estatais.

4 Destaca, ainda, Meirelles Teixeira: "É a esse arranjo, mediante o qual, pela distribuição de
competências, pela participação parcial de certos órgãos estatais controlam-se e limitam-se
reciprocamente, que os ingleses denominavam, já anteriormente a Montesquieu, sistema de "freios
recíprocos", "controles recíprocos", "reservas", "freios e contrapesos" (checks and controls, checks
and balances), tudo visando um verdadeiro "equilíbrio dos poderes" (equilibrium of powers) - o que
era natural, uma vez que todo o esforço do constitucionalismo inglês, ao longo dos vários séculos do
seu desenvolvimento, visava justamente estabelecer o equilíbrio politico entre os poderes do Rei e do
Parlamento, entre as prerrogativas da Coroa e as liberdades públicas" (p. 532) "O verdadeiro
problema, da organização constitucional, como bem observa Agesta, consiste, portanto, em
estabelecer as vias através das quais se há de realizar essa colaboração". (p. 534). 


\title{
3 A CRítICA DE LOEWENSTEIN E UM ADENDO: A PROPAGANDA POLITICA
}

Tratando da "anatomia do processo governamental" (1986, p.41), Karl Loewenstein refere a necessidade de uma classificação de Estados e formas de governo e não apenas como as instituições e técnicas estão "descritas nos textos constitucionais. Se uma classificação há de ter sentido", explicita, "terá de estar baseada numa análise da realidade política do processo governamental que, em geral, não poderá deduzir-se da constituição" (LOEWENSTEIN, 1986, p.42).

Assim, portanto, as formas de governo, "a distribuição e concentração do exercício do poder" conforme "uma antiga teoria: a "separação de poderes"" (LOEWENSTEIN, 1986, p.54).

\begin{abstract}
O dogma da equiparação do constitucionalismo e da separação de poderes encontrou sua formulação clássica no artigo 16 da Declaração francesa dos direitos do homem, de agosto de 1789: "Toda sociedade na qual a garantia dos direitos não está assegurada e a separação dos poderes determinada, não tem constituição. (...) O que na realidade significa a assim chamada "separação de poderes" não é, nem mais nem menos, que o reconhecimento de que por uma parte o Estado tem de cumprir determinadas funções - o problema técnico da divisão do trabalho - e que, por outra, os destinatários do poder encontram-se beneficiados se estas funções são realizadas por diferentes órgãos: a liberdade é o telos ideológico da teoria da separação de poderes.
\end{abstract}

Loewenstein chama a atenção, em certo momento, para uma questão muito atual, pertinente à análise de corrupção - de toda forma de corrupção, dá mais sutil à mais evidente:

O que nem Locke, nem Montesquieu, nem a Revolução francesa, para sua própria desgraça, não viram ou não quiseram ver - e isto é compreensível dado que sua intenção ideológica se dirigia contra o absolutismo tradicional - é que todo governo é poder. Sua racionalização do processo do poder governamental induziu-os a acreditar que o poder podia ser neutralizado e que seu caráter demoníaco podia ser exorcizado. As inevitáveis consequências desta atitude foram, primeiro, o Terror imposto pela Convenção e, após outro período de caos político, a ditadura napoleônica" (LOEWENSTEIN, 1986, p.54). 
Detendo-se nos "Controles do poder político", Loewenstein (1986, p.149151) apresenta a Constituição como "dispositivo de controle do poder":

Cada sociedade estatal, qualquer que seja sua estrutura social, possui certas convicções compartilhadas e certas formas de conduta reconhecidas que constituem, no sentido aristotélico de "politéia", sua "constituição". (...) Num sentido ontológico, dever-se-á considerar como o telos de toda constituição a criação de instituições para limitar e controlar o poder político".

\title{
“A liberdade política e a propaganda" (LOEWENSTEIN,1986, p.412)
}

Quando trata da liberdade politica(ponto básico da teoria de Montesquieu) e a propaganda, Loewenstein detém-se na "circulação das ideologias políticas", na "propaganda política e os meios de comunicação de massa", porquanto:

\begin{abstract}
Os sistemas políticos e suas instituições estendem-se, em primeira linha, pela divulgação das ideologias que os sustentam e promovem. A difusão das ideologias - sua "circulação ou mobilidade" - depende da "receptividade" dos destinatários do poder, sua disposição para aceitá-las e para deixar-se guiar por elas. (....) A propaganda política é um intento de influir na massa dos destinatários do poder, operando, portanto, mais com efeito emocionais do que com a persuasão mediante argumentos racionais. Para alcançar o público, as idéias e as questões políticas difundidas pela propaganda serão simplificadas, apresentadas superficialmente e até exageradas (...) Dado que está destinada a ser aceita e digerida pela massa, a propaganda política não apresenta o pró e o contra de uma questão para informar e educar os destinatários do poder, permitindo-lhes formar-se sua própria opinião". (...) Venderá uma opinião política como uma mercadoria; (..) Intentará embotar e excluir o raciocínio individual e superar a resistência oposta à opinião oferecida até que o consumidor, finalmente, se decida pela fórmula política em questão, persuadido de que a escolhe por um ato livre de sua vontade". (...) Ou, parafraseando a "lei" de Sir Harold Mackinder: Quem domina os meios de comunicação de massas domina o eleitorado; quem domina o eleitorado, domina o processo político (LOEWENSTEIN, 1986, p.412-417).
\end{abstract}

A teoria da corrupção deverá alcançar, portanto, a área da comunicação, em termos de "marketing" político, de modo a abranger os comportamentos sociais para 
a implantação de ideologias, anotando-se o registro de Mario Stoppino no "Dicionário de Política" (BOBBIO, 1986):

No seu significado fraco, Ideologia designa o genus, ou a species diversamente definida, dos sistemas de crenças políticas: um conjunto de ideias e de valores respeitantes à ordem pública e tendo como função orientar os comportamentos políticos coletivos. O significado forte tem origem no conceito de Ideologia de Marx, entendido como falsa consciência das relações de domínio entre as classes (...) a Ideologia é uma crença falsa. (...) No significado fraco, Ideologia é um conceito neutro, que prescinde do caráter eventual e mistificante das crenças políticas. No significado forte (Marx), Ideologia é um conceito negativo que denota precisamente o caráter mistificante de falsa consciência de uma crença política. (...) E o caráter da Ideologia é atribuído a uma crença, a uma ação ou um estilo político pela presença, neles, de certos elementos típicos, como o doutrinarismo, o dogmatismo, um forte componente passional, etc., que foram diversamente definidos e organizados por vários autores".

Fica o importante registro.

\section{A CRISE DOS PODERES}

Como visto, Montesquieu deixou a ressalva de os Poderes "caminharem de acordo", para o que se torna necessária uma ação mútua, consciente e constante, de respeito à Constituição.

Assinala-se mais recentemente, entretanto, a chamada crise dos Poderes:

Imergimos numa severa crise política", refere Oscar Vilhena Vieira (2018, P.11) "com forte impacto de funcionamento das instituições. A disputa política e institucional tornou-se mais polarizada, e a sociedade, mais intolerante e conflitiva. Para muitos, nosso sistema constitucional entrou em crise. A batalha dos poderes, no entanto, tem sido travada a partir da retórica constitucional, ainda que utilizada de forma estratégica e eventualmente distorcida e cínica".

Glauco Salomão Leite (2017, p.847) anota: "Poder Judiciário legislador?" Relativamente à "expansão da jurisdição constitucional" em termos do controle da constitucionalidade, invoca a "reiterada omissão legislativa" em casos como o 
mandado de injunção, referindo em conclusão: "Com todas as transformações que se verificaram no manejo do mandado de injunção, fica claro como a Corte expandiu seus poderes político - normativos. Ela abandonou a posição inicial, que se restringia a pronunciar a inércia do legislador, cientificando - o da mora legislativa.

\begin{abstract}
A reiterada omissão legislativa revelou que esse modelo de decisão não era satisfatório para assegurar o exercício de direitos fundamentais não regulados. Em outros termos, diante da eficácia limitada de preceitos constitucionais que exigiam norma integradora, o STF também produzia decisões ineficazes. O estado de anomia, portanto, subsistia. Porém, ao se promover um a guinada em sua jurisprudência, a Corte firmou sua competência para suprir o vazio normativo, permitindo o exercício do direito subjetivo, inicialmente no caso concreto. $O$ ápice desse movimento se deu com o reconhecimento da eficácia erga omnes das decisões em mandado de injunção, perfazendo um ciclo que eleva os poderes do STF afastando-o, cada vez mais, da imagem do legislador negativo.
\end{abstract}

Precisamente, porém, descabia ao Supremo assumir a função legislativa, mesmo "para assegurar o exercício de direitos fundamentais não regulados", conforme referido.

A crise dos Poderes envolve, conforme se verifica, a própria finalidade do Estado, na acepção de Dalmo A. Dallari (2012, p.122), "a ordem jurídica soberana que tem por fim o bem comum de um povo situado em determinado território, (DALLARI, 2012, p.122) sendo o bem comum, "o conjunto de todas as condições de vida social que consintam e favoreçam o desenvolvimento integral da personalidade humana."

Conforme define Montesquieu (2012, p.144) no Livro Oitavo de "O espírito das leis", tratando "Da corrupção dos princípios dos Três Governos": "A corrupção de cada Governo começa quase sempre pela corrupção dos seus princípios".

E assim percorre e analisa a corrupção do princípio de república, da democracia, da igualdade, da própria aristocracia, da monarquia, concluindo com "os efeitos da corrupção dos princípios":

1. Uma vez corrompidos os princípios do Governo, as melhores leis tornamse más, e prejudicam o Estado. Quando os princípios estão sadios, as más leis têm o efeito de boas. 2. Quando uma República é corrompida, não há remediar-se qualquer dos males resultantes, a não ser afastando a própria 
corrupção e restabelecendo os princípios. Qualquer outro corretivo, será ou inútil ou um novo mal.

Corrupção, do latim corruptio, de corrumpere (estragar, destruir, adulterar) nas suas várias acepções, compreende: 1. Ação ou efeito de corromper, de fazer degenerar; 2. Suborno, inclusive a corrupção linguística, em contrário ao período clássico.

Palavra transposta à área estatal, passa a receber numerosos e específicos estudos (GARCIA, 2016).

\section{COMO E PORQUE UM ESTADO SE CORROMPE" (DOBEL)}

Trata-se da Teoria da Corrupção, apresentada por John Patrick Dobel, a partir de cinco autores, Tucídides (1980, p.117-118; p.119-141), Platão, Aristóteles, Maquiavel e Rousseau, para chegar a "um dos problemas recorrentes da política - a corrupção do Estado, conforme explicita:

A Teoria da corrupção compreende as seguintes proposições: 1.Certos padrões de lealdade moral e virtude cívica são necessários para manter uma ordem política justa, equitativa e estável. A privatização das preocupações morais e a decorrente ruptura da lealdade e da virtude civís são os atributos cardeais de um Estado corrupto. 2. A grande desigualdade de riqueza, poder e status, criada pela capacidade humana de egoísmo e orgulho, gera a corrupção sistemática do Estado. Os membros das classes mais altas sacrificam sua lealdade civil básica para ganhar posições ou mantê-las, e a desigualdade estabelecida solapa a lealdade e o bem-estar substantivo dos cidadãos em geral. 3 . Essa mudança da qualidade moral da vida do cidadão, combinada com a desigualdade, gera facções. As facções são centros objetivos de riqueza, poder, polícia e política que, por sua própria dinâmica, usurpam funções políticas e governamentais de importância vital. A política facciosa acarreta a tentativa sistemática de corromper as agências. públicas e a lei. Ser membro de uma facção e praticar o faccionismo muda o caráter moral das pessoas, solapa sua lealdade à comunidade e estimula o egoísmo radical ou uma lealdade limitada às próprias facções. 4. O conflito de facção e a contínua desigualdade estendem a corrupção a toda a cidadania. A violência torna-se cada vez mais o substrato dominante de todas as relações e o discurso político fica reduzido a uma racionalização transparente. A função pública, a lei e a justiça transformam-se em instrumentos das facções e das classes. A população destituída e as classes altas tornam-se cada vez mais polarizadas. A política facciosa e demagógica, os levantes esporádicos e a 
cooptação passam a marcar as relações políticas, à medida que a sociedade gira num ciclo irrequieto de tentativas abortadas de 'restauração' e 'reforma', rumo à alienação, à violência e à anarquia institucional, cada vez maiores. 5. A socialização da educação, da vida familiar, da religião e dos militares também sustenta os valores comunais e a lealdade, por vezes até mesmo depois da corrupção do processo político. A corrupção final do Estado envolve o fracasso dos cidadãos em apoiar voluntariamente essas estruturas primárias. ${ }^{5}$

\title{
6 O ESTADO E A LEI FUNDAMENTAL
}

Comenta Celso Lafer (2019, p.2) que 'a dicotomia bom governo/mau governo é um dos temas clássicos da teoria política.

\begin{abstract}
Passa pelo "governo das leis" e pelo exercício do poder em prol de um ideal e uma prática voltada para o bem comum. Um dos ingredientes que desde os gregos e de toda a literatura subsequente leva à desagregação do bom governo, como lembra Bobbio, é a prevalência da formação de facções e o estimulo à discórdia.
\end{abstract}

Todo o exposto leva à consideração da necessidade de uma discussão ampla, constante, abrangente, nacional, esclarecendo mentes e levando às responsabilidades de cada qual.

O Estado - pessoa jurídica de Direito Público compõe-se, como faz visualizar a conhecida capa original do "Leviatã" - o corpo do soberano formado por milhares de pequeninos súditos, assim definido:

\footnotetext{
${ }^{5}$ Explica o autor: "Focalizamos a igualdade por causa da sua relação com o bem comum. Conforme está implícito nas palavras, o bem comum traz consigo, ao menos parcialmente, a ideia de bens que são igualmente comuns a todos os cidadãos. Dado o egoísmo humano e os conflitos normais de um Estado, manter o bem comum exige certa lealdade aos outros homens e às políticas e instituições que garantem aquele bem. A lealdade declina sob a pressão da desigualdade quando os indivíduos buscam objetivos puramente egoístas ou agem segundo o interesse limitado de uma facção. (...) Contudo", ressalva, "a teoria jamais supõe que toda desigualdade seja injusta e corruptora. As exigências práticas de uma sociedade exigem certa desigualdade nos reinos da economia e da política. A teoria distingue a desigualdade justa e razoável daquela que gera corrupção. O Estado que não é corrupto assegura certas formas básicas de igualdade econômica, jurídica e política, mas não exige uma igualdade absoluta em todos os aspectos da vida. Toda desigualdade razoável pode ser justificada, desde que contribua para o bem geral ou, pelo menos, não ponha em risco as liberdades substanciais dos cidadãos".
} 
Uma pessoa de cujos atos uma grande multidão, por pactos mútuos, realizados entre si, foi instituída por cada um como autor, com o objeto de que possa utilizar a força e meios de todos, conforme julgar oportuno, para assegurar a paz e a defesa comum (HOBBES, 1994, p.141).

Em "Ao leitor sem medo" (HOBBES, 1984, p.43), Renato Janine Ribeiro explica:

O pensamento hobbesiano não é assim do despotismo (à Montesquieu) nem só do absolutismo (à Luís XIV), é da soberania: reconhecer, no interior do corpo político, um poder soberano perante o qual nenhum privilégio localizado, nenhum direito adquirido subsista; fundar tal poder na representação, fazendo este foco central haurir dos súditos a sua força. ${ }^{6}$

$\mathrm{Na}$ atualidade constitucional, "Todo o poder emana do povo...": (Constituição Federal, P. Único, art. $1^{\circ}$ ):

\begin{abstract}
Trata-se do reconhecimento de que, na ordem política brasileira, o povo é o titular do poder. A pergunta que pode ser feita é: quem é o povo? A literatura política contemporânea diverge muito nesse ponto. No Brasil, sob a égide da Carta, povo é o conjunto dos cidadãos que participam direta ou indiretamente no processo político, seja por meio de eleições livres, seja pelo uso dos mecanismos diretos de exercício do poder, expostos no art. 14 (plebiscito, referendo e iniciativa popular). Assim, ao povo devem ser dadas satisfações por seus mandatários, que necessariamente deverão exercer o mandato em nome e para o bem dele, como um todo e não apenas à parcela que os elegeu (FERRAZ FILHO, 2012, p.6).
\end{abstract}

Afirmativa que mostra e afasta, para ser combatida, a corrupção dos exercentes do poder estatal, mediante os instrumentos do conhecimento, do debate, do diálogo, da justiça - enfim, da participação cidadã, nos termos e na conformidade da Lei Fundamental, a Constituição do País.

Para tanto, voltando à Teoria de Dobel, o fortalecimento das estruturas primárias destacando-se, precipuamente, como básicas e imediatas, a educação

\footnotetext{
6 "A volta do Estado Leviatã", entrevista de Sergio Lazzarini, "Veja" 16/10/2013: O intervencionismo estatal está aumentando no Brasil? Sem dúvida. Há um retorno ao que eu chamo de "Leviatã Majoritário" (o filósofo inglês tomas Hobbes definiu o Estado como um monstro, o Leviatã, com poder absoluto sobre os indivíduos) (...) Com as privatizações na década de 90 , passou-se ao estágio do "Leviatã minoritário". O governo continuou presente nas empresas, mas com um poder menor. Isso aconteceu principalmente por meio dos fundos de pensão e do Banco Nacional de Desenvolvimento Econômico e Social (BNDES), que viraram grandes acionistas".
} 
caminho da liberdade (GUIDE, 2002, p.171) e a família, "base da sociedade" (Constituição, art. 226).

De uma forma de educação política, objetivando o ensino da Constituição, adequadamente, desde o Ensino Fundamental ao Ensino Médio, "para o exercício da cidadania" (Constituição, art. 205).

\section{CONCLUSÃO}

Conforme visto, Dobel aponta possibilidades de enfrentamento à corrupção do Estado, sendo uma delas o que denomina a socialização da educação, ou seja, "o desenvolvimento do sentimento coletivo, da solidariedade social e do espirito de cooperação nos indivíduos associados" em termos ${ }^{7}$ de "lealdade moral e virtude cívica", - pelo instrumento da educação, para a efetivação da cidadania, fundamento do Estado (Constituição, art. 1ํㅡ. II).

\section{REFERENCIAS}

AURÉLIO. Dicionário folha. Nova fronteira, RIO DE JANEIRO.

BOBBIO, Noberto; MATTEUCCI, Nicola; PASQUINO, Gianfranco. Dicionário de Política. UNB, 1986

DALLARI, Dalmo de Abreu. Elementos de teoria geral do estado. Saraiva, São Paulo, 2012.

"DO LATIM CORRUPTIO, AÇÃO OU EFEITO DE CORROMPER, DE FAZER DEGENERAR" (LAROUSSE CULTURAL, NOVA CULTURAL, 1998)

GARCIA, Maria. Corrupção do estado e a constituição de 1988. Reforma política e o recall. In: corrupção. Caderno especial. Revista dos Tribunais, VOL. 967, MAIO 2016

7 Dicionário Folha / Aurélio, Nova Fronteira, Rio de Janeiro 
GIDE, André. Educação é liberdade. In: 365 reflexões sobre a arte de ensinar. publifolha, são paulo, 2002.

HAURIOU, André. Droit constitutionnel et institutions politiques". MONTCHRESTIEN, PARIS, 1975,

HOBBES, Thomas. Leviatã. 1994.

Hobbes escrevendo contra o seu tempo. Brasiliense, São Paulo, 1984. FERRAZ FILHO, José Francisco Cunha. Constituição federal interpretada. Manole, São Paulo, 2012.

"INTERPRETAÇÃO DA CONSTITUIÇÃO E ALTERAÇÃO DO TEXTO DA CONSTITUIÇÃO POR DECISÃO JUDICIAL.

LAFER, Celso. A democracia e a nossa conjuntura. In: Estadão. 2019.

LEITE, George Salomão; STRECK, Lenio; NERY JR., Nelson. Ativismo judicial. In crise dos poderes da república. Judiciário, legislativo e executivo. Revista dos tribunais, SÃO PAULO 2017, PP. 847 E SEGS.

MONTESQUIEU; MOTA, Pedro Vieira. O espírito das leis: as formas de governo, a federação, a divisão dos poderes, presidencialismo versus parlamentarismo. Saraiva, 1987.

SILVA, José Afonso da. Comentário contextual à constituição. Malheiros, 2005.

TEIXEIRA, J. H. Meirelles. Curso de direito constitucional, 2 ${ }^{\mathrm{a}}$ Edição, Conceito, São Paulo, 2011.

"TEORIA DE LA CONSTITUCIÓN", ARIEL DERECHO, BARCELONA, 2ª EDIÇÃO, 1986, PP. 41 E SEGS. TRADUÇÃO LIVRE.

VIEIRA, Oscar Vilhena. A batalha dos poderes: Da transição democrática ao malestar constitucional. COMPANHIA DAS LETRAS, 2018, PP. 11.

WEBER, Max. Economia e sociedade. Ed. UNB,3를 EDC̃A, 1994. 